\title{
Alelopatia do extrato aquoso e do óleo essencial de folhas do manjericão "Maria Bonita" na germinação de alface, tomate e melissa
}

\author{
ROSADO, L.D.S.; RODRIGUES, H.C.A.; PINTO, J.E.B.P.*; CUSTÓDIO, T.N.; PINTO, L.B.B.; BERTOLUCCI, \\ S.K.V. \\ Departamento de Agricultura, Setor de Cultura de Tecidos e Plantas Medicinais, Universidade Federal de Lavras \\ (UFLA), Caixa Postal 3037, CEP: 37200-000, Lavras-Brasil. *jeduardo@ufla.br
}

\begin{abstract}
RESUMO: O objetivo deste trabalho foi estudar o efeito alelopático do extrato aquoso e do óleo essencial de folhas frescas de Ocimum basilicum L. 'Maria Bonita' no índice de velocidade de germinação, comprimento de raízes e porcentagem de germinação da alface (Lactuca sativa L.), de tomate (Lycopersicum esculentum Mill.), e de melissa (Melissa officinalis L.). Os extratos foram obtidos pela trituração das folhas frescas e o óleo essencial extraído por hidrodestilação das folhas durante $90 \mathrm{~min}$. Foram utilizadas duas formas de aplicação, extrato aquoso e óleo essencial, cinco concentrações $(0,0 ; 0,001 ; 0,01 ; 0,1$ e 1,0\% v/v), em delineamento inteiramente casualizado, com cinco repetições, com 25 sementes de cada espécie por placa, totalizando 25 parcelas para cada espécie. Através dos resultados obtidos pode-se concluir que os extratos aquosos de manjericão apresentaram efeito significativo apenas para o índice de velocidade de germinação das sementes de tomate e para comprimento de raízes da alface e da melissa. $O$ óleo essencial do manjericão apresentou potencialidades alelopáticas inibitórias em sementes de alface, de tomate e de melissa afetando o índice de velocidade de germinação, o comprimento das raízes e a porcentagem de germinação.
\end{abstract}

Palavras-chave: Ocimum basilicum, alelopatia, composição química, germinação

\begin{abstract}
Allelopathy of aqueous extract and essential oil of leaves from basil "Maria Bonita" on lettuce, tomato and melissa germination. The aim of this work was to study the allelopathic effect of aqueous extract and essential oil of fresh leaves from Ocimum basilicum L. 'Maria Bonita' on germination velocity index, root length and germination percentage of lettuce (Lactuca sativa L.), tomato (Lycopersicum esculentum Mill.), and melissa (Melissa officinalis L.). The extracts were obtained by grounding fresh leaves and the essential oil was extracted through hydrodistillation of the leaves during $90 \mathrm{~min}$. Two application forms were used, aqueous extract and essential oil, five concentrations $(0.0 ; 0.001 ; 0.01 ; 0.1$ and $1.0 \% \mathrm{v} / \mathrm{v})$, in completely randomized design, with five replicates including 25 seeds of each species per plot, totaling 25 plots for each species. The obtained results indicated that the aqueous extracts of basil presented a significant effect only for the germination velocity index of tomato seeds, as well as for lettuce and melissa root length. Basil essential oil presented allelopathic inhibitory potential in lettuce, tomato and melissa seeds, affecting germination velocity index, germination percentage and seedling root length.
\end{abstract}

Key words: Ocimum basilicum, allelopathy, chemical composition, germination

\section{INTRODUÇÃO}

A alelopatia tem sido descrita como um processo pelo qual produtos do metabolismo secundário de determinado vegetal são liberados, impedindo a germinação e o desenvolvimento de outras plantas relativamente próximas (Soares \& Viera, 2000).
O princípio ativo das plantas medicinais e aromáticas é mediado por meio de substâncias químicas pertencentes a diferentes categorias de compostos, tais como fenóis, terpenos, alcalóides, poliacetilenos, ácidos graxos, peptídeos, entre outros

Recebido para publicação em 20/10/2008

Aceito para publicação em 08/04/2009

Rev. Bras. Pl. Med., Botucatu, v.11, n.4, p.422-428, 2009. 
(Periotto et al., 2004). Quando estes compostos apresentam alguma propriedade inibitória, pode afetar a germinação de sementes de várias espécies, sendo a sensibilidade destas, variável com a concentração aplicada (Hruska et al., 1982).

Pesquisas têm mostrado os efeitos dos extratos aquosos e dos óleos essenciais sobre a germinação de diferentes espécies (Alves et al., 2004; Maraschin-Silva \& Aquila, 2006; Souza-Filho, 2006; Piccolo et al., 2007). Na maioria das espécies, o efeito alelopático é mais evidente quando utilizados extratos de folhas (Souza et al., 2007).

O Ocimum basilicum L. 'Maria Bonita' é uma planta aromática e medicinal pertencente à família Lamiaceae. Conhecida popularmente como manjericão ou alfavaca, apresenta grande importância econômica. O óleo essencial presente nessa cultivar apresenta elevada quantidade de linalol (82,64\%), segundo Blank et al. (2007), sendo muito utilizado no preparo de perfumes, cosméticos, repelentes de insetos, antiinflamatória, dentre outras (Teixeira et al., 2002; Rabelo et al., 2003).

As investigações de plantas com atividade alelopática podem ser úteis na busca de fitotoxinas com potencial para compor novos agroquímicos, sendo altamente importante a realização de pesquisas nesse campo para se conhecer os mecanismos de ação, produção e decomposição de compostos alelopáticos.

Pouco se sabe sobre os efeitos alelopáticos do óleo essencial de manjericão (Ocimum basilicum L.) sobre as espécies cultivadas, portanto o objetivo do presente trabalho foi estudar os possíveis efeitos alelopáticos de extratos aquosos e do óleo essencial de manjericão na porcentagem de germinação, no índice de velocidade de germinação e no comprimento das raízes de alface (Lactuca sativa $L$.), de tomate (Lycopersicon esculentum Mill.) e de melissa (Melissa officinalis L.).

\section{MATERIAL E MÉTODO}

\section{Material vegetal}

O trabalho foi conduzido no laboratório de cultura de tecidos e plantas medicinais da UFLA. A cultivar 'Maria Bonita' é proveniente do acesso PI 197442 obtido do Banco de Germoplasma do "North Central Regional PI Station" lowa State University, EUA. Sementes de Ocimum basilicum L. dessa cultivar foram semeadas in vitro em meio MS (Murashige \& Skoog, 1962). Após 30 dias as plantas cultivadas in vitro foram aclimatizadas no substrato comercial Plantmax ${ }^{\circledR}$ em bandeijas de isopor. Posteriormente, as plantas foram transplantadas para vasos de $10 \mathrm{~L}$ com areia, Plantmax ${ }^{\circledR}$ e matéria orgânica, na proporção (1:1:1) mantidas em casa de vegetação e irrigadas com água diariamente. Plantas com cerca de 2 meses tiveram as folhas colhidas na parte da manhã, levadas ao laboratório para obtenção do extrato aquoso da folha fresca e para extração óleo essencial.

\section{Obtenção dos extratos}

O extrato aquoso foi obtido, a frio por turbólise (emprego do liquidificador industrial na trituração de partes vegetais). Foram utilizados $150 \mathrm{~g}$ de folhas frescas para $1 \mathrm{~L}$ de água destilada.

Para obtenção do óleo essencial foram utilizados $40 \mathrm{~g}$ de massa fresca das folhas que foram transferidas para balões volumétricos de $2 \mathrm{~L}$, acrescentando $1,5 \mathrm{~L}$ de água destilada. Foram realizadas oito extrações do óleo essencial das folhas de manjericão, obtendo-se no final uma amostra composta. Estas extrações foram realizadas pelo processo de hidrodestilação durante 90 min a partir da ebulição. Logo em seguida, o hidrolato foi submetido à partição líquido-líquido, em funil de separação, realizando-se três lavagens do hidrolato com três porções de $15 \mathrm{~mL}$ de diclorometano por 10 min cada. As frações orgânicas foram reunidas e secas com sulfato de magnésio anidro, deixando-o agir por 30 min e posteriormente, o sal foi removido por filtração simples e o solvente foi evaporado à temperatura ambiente em capela de exaustão de gases.

\section{Análise cromatográfica}

A análise da composição química do óleo essencial foi realizada no Laboratório de Cromatografia do Departamento de Química da Universidade Federal de Sergipe, por meio de uma amostra composta do óleo essencial das seis repetições de cada tratamento. As amostras de óleo foram analisadas por cromatografia gasosa, utilizando-se aparelho Shimadzu 17A equipado com detector de ionização de chama (FID) e também por cromatografia gasosa acoplada á espectrometria de massa (CG-EM), usando o aparelho Shimadzu QP5050A nas seguintes condições: coluna CBP-5 (Shimadzu) preenchida com coluna capilar de sílica ( $30 \mathrm{~m} \times 0,25 \mathrm{~mm}$ diâmetro interno $x 0,25 \mu \mathrm{m}$, filme composto defenilmetilpolisiloxano $5 \%$ ) conectado a um detetor quadrupólo operando em modo El a 70 eV com intervalo de massa entre 40$400 \mu$, a razão de $0,5 \mathrm{scan} / \mathrm{s}$; gás carreador: o gás Helio foi injetado no fluxo de de $1 \mathrm{~mL} \mathrm{~min}^{-1}$ (razão de fluxo de 1:20) com a temperatura de interface a $220^{\circ} \mathrm{C}$ e $240^{\circ} \mathrm{C}$, o volume de injeção foi de $0,2 \mu \mathrm{L}(20 \%$ em $\mathrm{CH}_{2} \mathrm{Cl}_{2}$ ) em fluxo e temperatura de $60^{\circ} \mathrm{C}$ a $246^{\circ} \mathrm{C}$, com um aumento de $3^{\circ} \mathrm{C} \mathrm{min}^{-1}$, após $10^{\circ} \mathrm{C} \mathrm{min}^{-1}$ para $270^{\circ} \mathrm{C}$, mantendo a temperatura final por $5 \mathrm{~min}$.

Os componentes foram identificados por comparação com dados de espectro de massa,

Rev. Bras. PI. Med., Botucatu, v.11, n.4, p.422-428, 2009. 
conforme Adams (2001) e por base de dados computadorizada usando biblioteca NIST (1998). As concentrações dos compostos foram calculadas a partir das áreas dos picos e expressos com valores aferidos em três análises.

\section{Atividade alelopática}

O extrato aquoso e o óleo do manjericão foram emulsionados com Tween 80 , na proporção de 1:1. A partir da solução emulsionada foram obtidas soluções aquosas nas concentrações de 0,$001 ; 0,01$; 0,1 e 1,0\% (v/v) e uma solução de Tween 80 a 1,0\% $(\mathrm{v} / \mathrm{v})$ foi usada como controle.

Foram utilizadas para o teste de germinação, cinco repetições contendo 25 sementes de cada espécie, que foram semeadas em placas de Petri (9 $\mathrm{cm}$ de diâmetro), tendo como substrato três folhas de papel de filtro, umedecidas com volume de água destilada equivalente a três vezes a massa do papel seco. Logo após a semeadura da alface, tomate e melissa, $3 \mathrm{~mL}$ da solução de cada concentração do extrato aquoso e do óleo essencial foram distribuídos em dois papéis de filtro, colados na tampa da placa, ou seja, na parte de cima evitando o contato direto das sementes tanto com o óleo, quanto com o extrato. Em seguida, essas placas foram mantidas em sala de crescimento a temperatura de $26 \pm 1^{\circ} \mathrm{C}$ e fotoperíodo de $16 \mathrm{~h}$ luz, sob intensidade luminosa de $25 \mu \mathrm{mol} \mathrm{m}^{-2} \mathrm{~s}^{-1}$.

A avaliação do potencial alelopático do extrato aquoso e do óleo essencial foi realizada pela determinação da porcentagem de germinação, do índice de velocidade de germinação e comprimento das raízes $(\mathrm{cm})$ das plântulas.

A avaliação dos resultados foi realizada no primeiro dia em que as plantas começaram a germinar (protrusão da radícula) sendo esta ocorrência observada no terceiro dia após a semeadura. Avaliouse por sete dias consecutivos a emissão da radícula para o cálculo do índice de velocidade de germinação (IVG) e no sétimo dia a porcentagem de germinação e o comprimento das raízes.

\section{Análise estatística}

O delineamento experimental utilizado foi o inteiramente casualizado, em esquema fatorial $(2 \times 5)$ com duas formas de aplicação e cinco doses do extrato e do óleo, com 5 repetições por tratamento, com 25 sementes por placa, sendo cada placa perfazendo uma parcela.

A porcentagem $(G)$ e a velocidade $(V)$ de germinação foram calculadas com o uso das seguintes fórmulas, conforme Laboriau \& Valadares (1976).

a) $G=(N / A) \cdot 100$

Onde: $\mathrm{N}=$ número total de sementes germinadas; $A=$ número total de sementes colocadas para germinar. b) $\mathrm{V}=\left(\sum \mathrm{ni}\right) /\left(\sum \mathrm{ni} \cdot \mathrm{ti}\right)$

Onde: $\mathrm{ni}=$ Número de sementes germinadas dentro de um intervalo de tempo (ti-1) - (ti).

Os dados foram submetidos à análise de variância e as médias foram comparadas por meio do teste de regressão não-linear, no programa SAS (SAS, 1999).

\section{RESULTADO E DISCUSSÃO}

Com base nos resultados obtidos, observouse que a ação do extrato aquoso de folhas frescas de manjericão para o índice de velocidade de germinação (IVG) das sementes de alface, tomate e melissa, demonstrou que não houve diferença estatística para a variável analisada em alface e melissa. Estudos recentes mostram que, embora a porcentagem final de germinação possa não ser significativamente afetada pela ação de aleloquímicos, o padrão de germinação pode ser modificado, verificando-se diferenças na velocidade e na sincronia da germinação de sementes submetidas a tais compostos (Santana et al., 2006). Entretanto, para o tomate apenas as concentrações 0,1 e $1.0 \%$ foram menores e estatisticamente diferentes, causando significativa redução no IVG em relação aos demais tratamentos, indicando assim menor vigor das sementes (Tabela 1).

Para o comprimento das raízes houve diferença significativa para doses do extrato aquoso em sementes de alface e melissa (Tabela 1). Para alface as doses controle e $0,001 \%$, proporcionaram os maiores comprimentos da raiz e para melissa a dose de $1 \%$ apresentou menor comprimento desta, evidenciando efeito alelopático para esta variável.

As porcentagens de germinação de alface, melissa e tomate não foram influenciadas pelas concentrações dos extratos aquosos de manjericão (Tabela 1).

Segundo Rodrigues et al. (1999), os compostos alelopáticos são inibidores de germinação e crescimento, pois interferem na divisão celular, permeabilidade de membranas e na ativação de enzimas.

Lustosa et al. (2007) observaram que para a variável porcentagem de germinação, tanto o extrato aquoso de Piper aduncum quanto o de Piper tectoniifolium mostraram efeito alelopático significativo sobre as sementes de alface, sendo que, quanto maior a concentração do extrato maior o número de sementes não germinadas. Pesquisas de Wandscheer \& Pastorini (2008) verificaram que para sementes de tomate, somente o extrato de folha $10 \%$ reduziu a porcentagem de germinação e o comprimento radicular do epicótilo. No entanto, extratos de folhas e raiz $10 \%$ causaram atraso no processo germinativo e no número de plântulas

Rev. Bras. PI. Med., Botucatu, v.11, n.4, p.422-428, 2009. 
TABELA 1. Médias do índice de velocidade de germinação de alface (IVG-A), tomate (IVG-T) e melissa (IVG-M); Comprimento das raízes da alface (CR-A), tomate (CR-T) e melissa (CR-M); e porcentagem de germinação da alface (Ger-A), tomate (Ger-T) e melissa (Ger-M) sob o efeito do extrato aquoso do manjericão.

\begin{tabular}{cccccccccc}
\hline $\begin{array}{c}\text { Extrato aquoso } \\
(\% \text { VN })\end{array}$ & IVG-A & IVG-T & IVG-M & $\begin{array}{c}\text { CR-A } \\
(\mathrm{cm})\end{array}$ & $\begin{array}{c}\text { CR-T } \\
(\mathrm{cm})\end{array}$ & $\begin{array}{c}\text { CR-M } \\
(\mathrm{cm})\end{array}$ & $\begin{array}{c}\text { Ger-A } \\
(\%)\end{array}$ & $\begin{array}{c}\text { Ger-T } \\
(\%)\end{array}$ & $\begin{array}{c}\text { Ger-M } \\
(\%)\end{array}$ \\
\hline Controle & $23,77 \mathrm{a}$ & $13,78 \mathrm{a}$ & $14,40 \mathrm{a}$ & $2,75 \mathrm{a}$ & $4,76 \mathrm{a}$ & $2,78 \mathrm{a}$ & $99 \mathrm{a}$ & $94 \mathrm{a}$ & $86 \mathrm{a}$ \\
& & & & & & & & & \\
0,001 & $23,44 \mathrm{a}$ & $12,13 \mathrm{a}$ & $13,76 \mathrm{a}$ & $3,12 \mathrm{a}$ & $5,94 \mathrm{a}$ & $2,64 \mathrm{a}$ & $98 \mathrm{a}$ & $92 \mathrm{a}$ & $88 \mathrm{a}$ \\
0,01 & $23,72 \mathrm{a}$ & $13,19 \mathrm{a}$ & $15,59 \mathrm{a}$ & $1,73 \mathrm{~b}$ & $6,49 \mathrm{a}$ & $2,74 \mathrm{a}$ & $96 \mathrm{a}$ & $98 \mathrm{a}$ & $72 \mathrm{a}$ \\
0,1 & $24,19 \mathrm{a}$ & $11,14 \mathrm{~b}$ & $12,59 \mathrm{a}$ & $1,18 \mathrm{~b}$ & $5,23 \mathrm{a}$ & $2,50 \mathrm{a}$ & $98 \mathrm{a}$ & $93 \mathrm{a}$ & $86 \mathrm{a}$ \\
1 & $23,52 \mathrm{a}$ & $9,84 \mathrm{~b}$ & $12,66 \mathrm{a}$ & $1,27 \mathrm{~b}$ & $4,97 \mathrm{a}$ & $1,50 \mathrm{~b}$ & $99 \mathrm{a}$ & $94 \mathrm{a}$ & $90 \mathrm{a}$ \\
\hline
\end{tabular}

* Médias seguidas da mesma letra na coluna, não diferem entre si pelo teste de Tukey, ao nível de 5\% de significância.

germinadas por dia, sendo o extrato de folha $10 \%$ mais ativo.

Pessotto \& Pastorini (2007) verificaram que na germinação da alface não houve diferença significativa entre os tratamentos com extratos de funcho a $1 \%$ e a $10 \%$, quando observado o IVG. Entretanto, observou-se que nas sementes de alface submetidas ao tratamento com funcho a $30 \%$, houve redução significativa do IVG em relação aos demais tratamentos, bem como o atraso no processo germinativo e a diminuição da porcentagem de germinação destas sementes, onde somente a $1 \%$ houve germinação das sementes de tomate, enquanto com extratos de funcho a $10 \%$ e a $30 \%$ não houve germinação.

Em trabalho realizado por Almeida et al. (2008), estudando o potencial alelopático in vitro de folhas de Leonorus sibiricus L. na germinação de espécies olericulas, concluíram que houve redução desta à medida que aumentavam as concentrações dos extratos aquoso e metanólico para sementes de Lactuca sativa. Por outro lado, sementes de

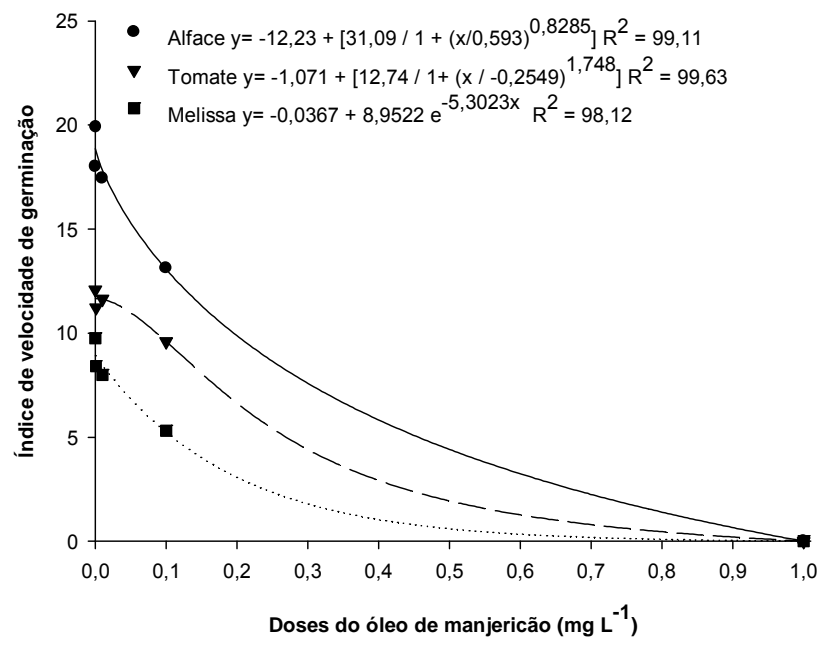

Raphanus sativum e Lepidium sativum não sofreram tais efeitos. Já para o comprimento radicular tanto as doses do extrato aquoso quanto do metanólico promoveram redução das mesmas, nas três espécies.

De acordo com análise de variância e teste de regressão não-linear, houve efeito significativo das doses do óleo essencial de manjericão.

Com relação ao IVG e comprimento da raiz, observou-se redução nos valores destas variáveis com o incremento nas doses de óleo essencial, apresentando valores nulos na dosagem de $1,0 \mathrm{mg}$ $\mathrm{L}^{-1}$ do óleo essencial de manjericão (Figura 1 ).

O comprimento da raiz da alface, tomate e melissa foi significativamente menor no tratamento com óleo essencial de manjericão a 1\% (Figura 1). Observando-se que tanto o epicótilo quanto o hipocótilo apresentaram-se pouco desenvolvidos. As folhas apareceram menores e mais escuras, porém na dose de $1 \%$ houve inibição completa da germinação (Figura 2), causando a morte da semente, evidenciando que a ação de vários aleloquímicos está envolvida na inibição e em modificações nos padrões

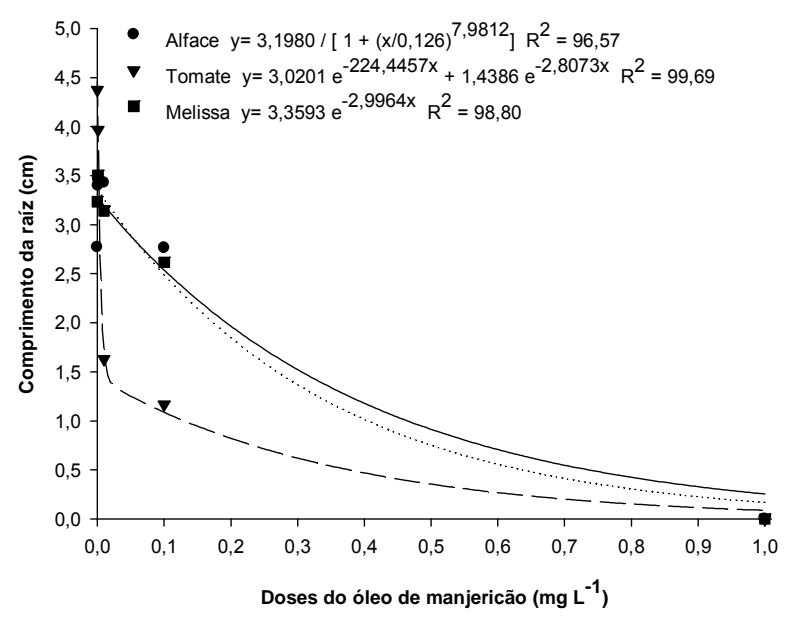

FIGURA 1. Efeito de doses crescentes do óleo essencial de manjericão sobre: Índice de velocidade de germinação (IVG) e comprimento das raízes de sementes de alface, tomate e melissa. 


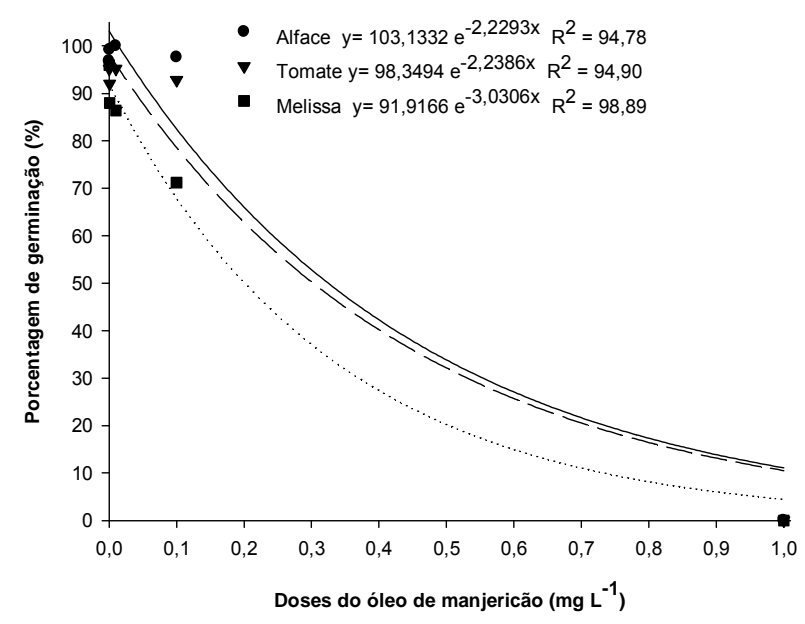

FIGURA 2. Porcentagem de germinação sementes de alface, tomate e melissa submetidas a doses crescentes do óleo essencial de manjericão.

de crescimento ou desenvolvimento das sementes.

Alves et al. (2004), estudando a alelopatia de extratos voláteis do óleo essencial, na germinação de sementes e no comprimento da raiz de alface, observaram que em alfavaca-cravo, apenas a concentração de $1,0 \%$ do óleo essencial teve efeito inibitório significativo sobre a germinação da alface, resultados semelhantes ao observado neste trabalho.

No que se refere à composição química, a análise por GC-MS do óleo de Ocimum basilicum 'Maria Bonita' identificaram a presença de oito compostos, 1,8-cineol, linalol, geraniol, $\alpha$-terpineol, acetato de geranila, $\alpha$-trans-bergamoteno, $\gamma$-cadineno e epi- $\alpha$-cadinol. As porcentagens de área dos picos correspondentes ao composto linalol é $78,35 \%$ e geraniol $15,95 \%$ sendo estes os componentes majoritários (Figura 3). Os dados obtidos das determinações qualitativas e quantitativas dos componentes principais presentes nas folhas frescas do óleo essencial de Ocimum basilicum L. estão apresentados na (Tabela 2).

Estudos recentes no âmbito fitoquímico revelaram que espécies da família Lamiaceae como Ocimum sp apresentam quantidades expressivas de substâncias voláteis (Zabaras \& Wyllie, 2001).

É possível que o monoterpeno linalol presente no manjericão, por ser o componente majoritário, seja o responsável pelos efeitos fitotóxicos nas sementes e no crescimento inicial das plântulas de alface, tomate e melissa. Os monoterpenóides formam a maioria dos óleos essenciais das plantas e são, dentro desse grupo, os que têm sido identificados com maior potencialidade inibitória. Diversas espécies de Salvia, Eucalyptus, Artemisia e Cassia occidentalis, elaboram produtos voláteis tóxicos como canfeno, dipenteno, $\alpha$-pineno e $\beta$-pineno que inibem o desenvolvimento de outras plantas (Almeida, 1988). Singh et al. (2002), estudando o efeito de quatro monoterpenos - citronelol, citronelal, cineol e linalol na germinação, crescimento e fisiologia de Cássia occidentalis sugerem que citronelal e linalol possuem potencial fitotóxico mais forte.

Variações de respostas foram observadas por Scrivanti et al. (2003), trabalhando com óleo essencial Tagetes minuta e Schinus areira, que avaliaram o efeito dos agentes alelopáticos no crescimento de raízes de milho e verificaram que o Tagetes minuta foi mais fitotóxico no tempo de 24 horas, devido ao componente químico ocimenone presente neste óleo. Da mesma forma, Jiménez-Osornio et al. (1996), estudando a atividade alelopática de Chenopodium ambrosioides L., verificaram que o óleo essencial apresentou efeito inibitório de $50 \%$ na germinação $P$. acutifolius e também atribuíram este fato a presença de componentes químicos presentes nesta espécie.

Sikkema et al. (1995) relataram que interações com monoterpenos de hidrocarboneto cíclico provocam alterações na estrutura e função das membranas o qual pode impedir o crescimento e

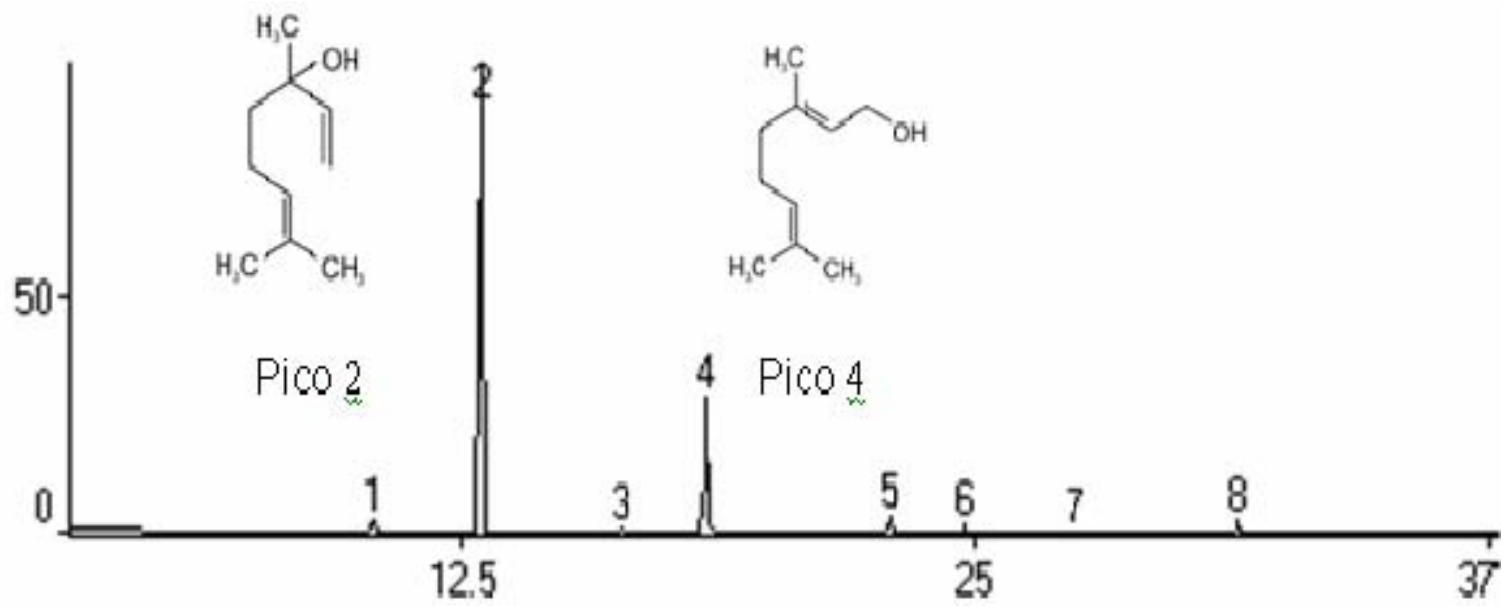

FIGURA 3. Cromatograma do óleo essencial de O. basilicum L. 
TABELA 2. Percentagem da área relativa dos picos cromatográficos correspondentes aos compostos identificados nas folhas frescas do óleo essencial de $O$. basilicum $L$.

\begin{tabular}{cccc}
\hline IK & Constituintes & Classe & GC- MS (\%) \\
\hline 1031 & 1,8-Cineol & $\mathrm{M}$ & 1,12 \\
1096 & Linalol & $\mathrm{M}$ & 78,35 \\
1188 & a-Terpineol & $\mathrm{M}$ & 0,59 \\
1252 & Geraniol & $\mathrm{M}$ & 15,94 \\
1381 & Acetato de geranila & $\mathrm{S}$ & 1,7 \\
1434 & a-trans- Bergamoteno & $\mathrm{S}$ & 0,7 \\
1513 & Y-Cadineno & $\mathrm{S}$ & 0,2 \\
1640 & epi-a-Cadinol & $\mathrm{S}$ & 1,4 \\
\hline$\%$ Total dos monoterpenos (M) & 96,00 \\
\hline Total dos sesquiterpenos (S) & 4,0 \\
\hline \multicolumn{5}{l}{} \\
\hline
\end{tabular}

atividade das células. Alem disso, normalmente a presença de flavonóides na solução pode causar uma diminuição do potencial osmótico causando com isso dificuldades na absorção de solutos através dos pêlos absorventes e consequentemente causando redução do crescimento radicular (Ferreira e Áquila, 2000).

\section{CONCLUSÃO}

O extrato aquoso de manjericão apresentou efeito inibitório apenas para o índice de velocidade de germinação do tomate e para comprimento de raízes da alface e da melissa.

O óleo essencial do manjericão apresentou potencialidades alelopaticas inibitórias em sementes de alface, tomate e melissa para a porcentagem de germinação, o índice de velocidade de germinação e para o comprimento das raízes.

\section{AGRADECIMENTO}

Ao Conselho Nacional de Desenvolvimento Científico (CNPq), a Coordenação de Aperfeiçoamento de Pessoal de Nível Superior (Capes) e a FAPEMIG pela concessão da bolsa de estudo e suporte financeiro.

\section{REFERÊNCIA}

ADAMS, R.P. Identification of essential oil components by gas chromatographylquadrupole mass sprestroscopy. Illinois: Allured Publishing Corporation, 2001. 456p.

ALMEIDA, L.F.R. et al. In vitro allelopathic potential of Leonurus sibiricus L. leaves. Journal of Plant Interaction, v.3, n.1, p.39-48, 2008.

ALMEIDA, F.S. A alelopatia e as plantas. Londrina: IAPAR, 1988. 60p.
ALVES, M.C.S. et al. Alelopatia de extratos voláteis na germinação de sementes e no comprimento da raiz de alface. Pesquisa Agropecuária Brasileira, v.39, n.11, p.1083-6, 2004.

BLANK, A.F. et al. Novas Cultivares Maria Bonita: cultivar de manjericão tipo linalol. Pesquisa Agropecuária Brasileira, v.42, n.12, p.1811-3, 2007.

FERREIRA, A.G.; AQUILA, M.E.A. Alelopatia: uma área emergente da ecofisiologia. Revista Brasileira de Fisiologia Vegetal, v.12, p.175-204, 2000.

HRUSKA, A.F.; DIRR, M.A.; POKORNY, F.A. Investigation of anthocyanc pigments and substances inhibitory to seed germination in the fruit pulp of Liriope muscari. Journal of the American Society for Horticultural Science, v.107, p.468-73, 1982.

JIMÉNEZ-OSORNIO, F.M.V.Z.J.; KUMAMOTO, J.; WASSER, C. Allelopathic Activity of Chenopodium ambrosioides L. Biochemical Systematics and Ecology, v.24, n.3, p.195-205,1996.

LABORIAU, L.G.; VALADARES, M.B. On the germination of seeds of Calotropis procera (Ait.) Ait. f. Anais da Academia Brasileira de Ciências, v.48, n.2, p.236-84, 1976.

LUSTOSA, F.L.F.; OLIVEIRA, S.C.C.; ROMEIRO, L.A. Efeito alelopático de extrato aquoso de Piper aduncum L. e Piper tectoniifolium Kunth na germinação e crescimento de Lactuca sativa L. Revista Brasileira de Biociências, v.5, supl.2, p.849-51, 2007.

MARASCHIN-SILVA, F.; AQÜILA, M.E.A. Potencial alelopático de espécies nativas na germinação e crescimento inicial de Lactuca sativa L. (Asteraceae). Acta Botânica Brasílica, v.20, n.1, p.61-9, 2006.

MURASHIGE, T.; SKOOG, F. A revised medium for rapid growth and bioassays with tobacco cultures. Physiologia Plantarum, v.15, p.473-97, 1962.

NATIONAL INSTITUTE OF STANDARDS AND TECHNOLOGY. PC version of the NIST/EPA/NIH Mass Spectral Database. Gaithersburg: U.S.Department of Commerce, 1998.

PERIOTTO, F. et al. Efeito alelopático de Andira humilis 
Mart. ex Benth na germinação e no crescimento de Lactuca sativa L. e Raphanus sativus L. Acta Botânica Brasílica, v.18, n.3, p.425-30, 2004. PESSOTTO, G.P.; PASTORINI, L.H. Análise da germinação de alface (Lactuca sativa L.) e tomate (Lycopersicon esculentum Mill.) sob a influência alelopática do funcho (Foeniculum vulgare Mill.). Revista Brasileira de Biociências, v.5, supl.2, p.990-2, 2007.

PICCOLO, G. et al. Efeito alelopático de capim limão e sabugueiro sobre a germinação de guanxuma. Ciências Agrárias, v.28, n.3, p.3816, 2007.

RABELO, M. et al. Antinociceptive properties of the essential oil of Ocimum gratissimum L. (Labiatae). Brazilian Journal Medical and Biological Research, v.36, p.521-4, 2003.

RODRIGUES, L.R.A.; RODRIGUES, T.J.D.; REIS, R.A. Alelopatia em plantas forrageiras. Guaíba: FUNEP/Jaboticabal, 1999. 18p.

SANTANA, D.G. et al. Germination meansurements to evaluate allelopathic interactions. Allelopathy Journal, v.17, p.43-52, 2006.

SAS INSTITUTE. Statistical Analysis System. Property software release. 8.ed. Cary: SAS Institute, 1999. 956p.

SCRIVANTI, L.R.; ZUNINO, M.P.; ZYGADLO, J.A.

Tagetes minuta and Schinus areira essential oils as allelopathic agents. Biochemical Systematics and Ecology, v.31, p.563-72, 2003.

SIKKEMA, J.; BONT, J.A.M.; POOLMAN, B. Mechanism of membrane toxicity of hydrocarbons. Revista de Microbiologia, v.59, n.2, p.201-22, 1995.

SOARES, G.L.G.; VIEIRA, T.R. Inibição da germinação e do crescimento radicular de alface (cv. "Grand rapids") por extratos aquosos de cinco espécies de Gleicheniaceae. Floresta e Ambiente, v.7, n.1, p.180-97, 2000.

SOUZA, C.S.M. et al. Alelopatia do extrato aquoso de folhas de aroeira na germinação de sementes de alface. Revista Verde, v.2, n.2, p.96-100, 2007.

SOUZA-FILHO, A.P.S. et al. Potencial alelopático de Myrcia guianensis. Planta daninha, v.24 n.4, p.649- 56, 2006.

SINGH, H.P. et al. Comparative phytotoxicity of four monoterpenes against Cassia occidentalis. Annals of Applied Biology, v.141, n.2, p.111-6, 2002.

TEIXEIRA, J.P.F. et al. Essential oil contents in two cultivars of basil cultivated on NFT-hydroponics. Acta Horticulturae, v.569, p.203-8, 2002.

WANDSCHEER, A.C.D.; PASTORINI, L.H. Interferência alelopática de Raphanus raphanistrum L. sobre a germinação de Lactuca sativa L. e Solanum lycopersicon L. Ciência Rural, v.38, n.4, p.949-53, 2008.

ZABARAS, D.; WYLLIE, S.G. The effect of mechanical wounding of the composition essential oil from Ocimum minimum $L$. leaves. Molecules, v.6, p.79-86, 2001. 